\title{
Unterschenkelfraktur (AO 42 A2)
}

\author{
Karl Heinrich Winker
}

Patient, männlich, 27 Jahre alt

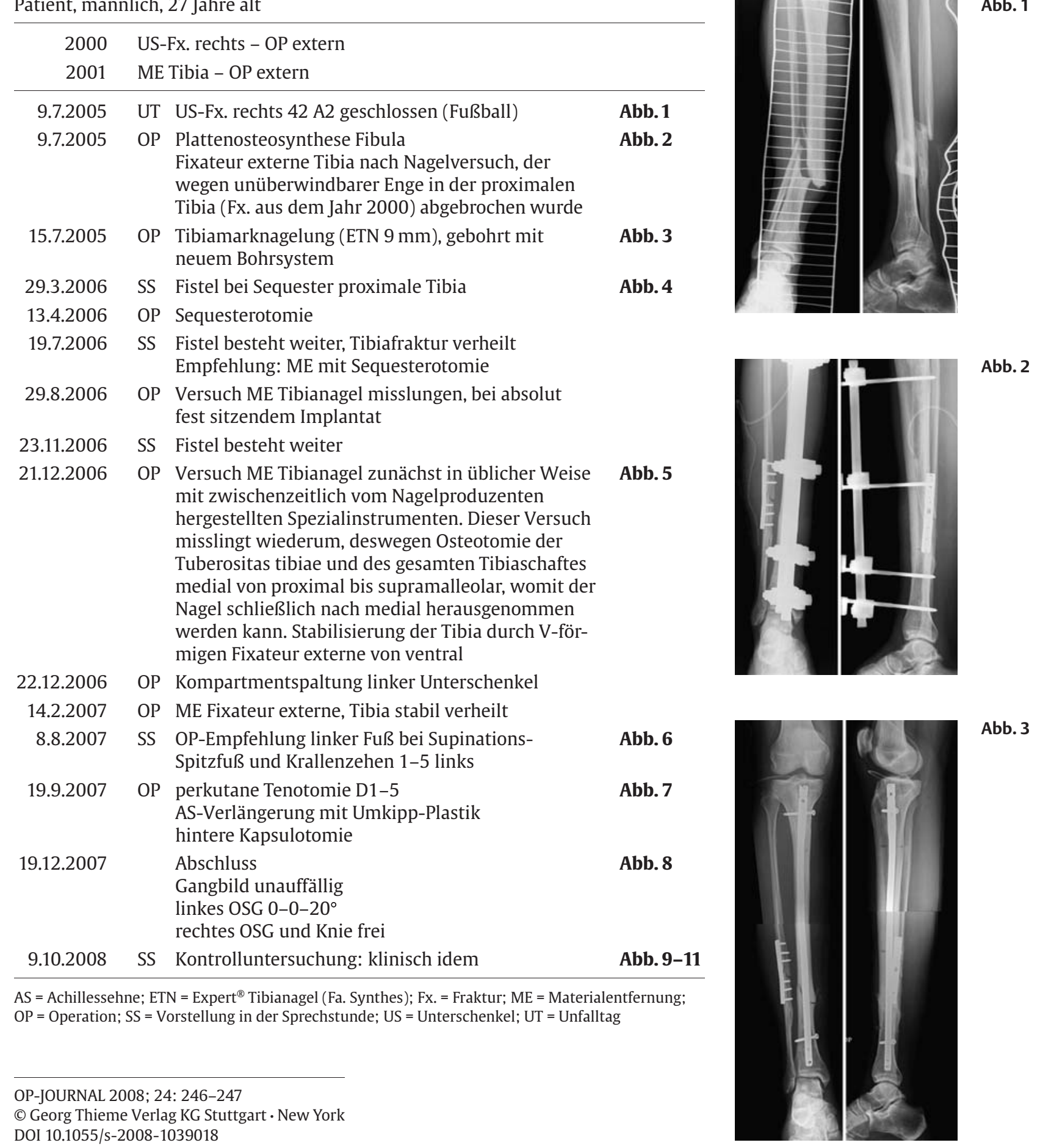




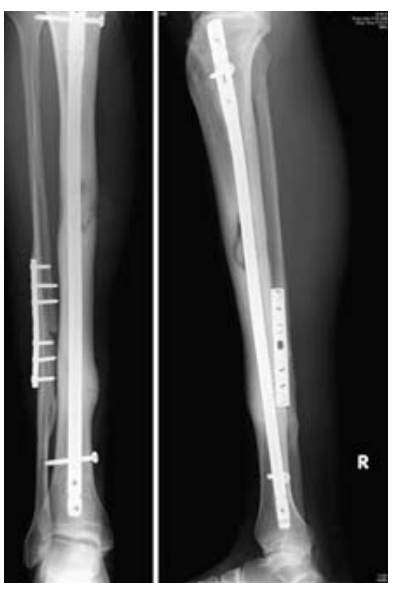

Abb. 4

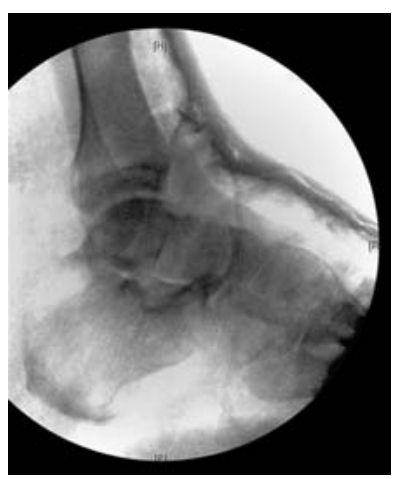

Abb. 7

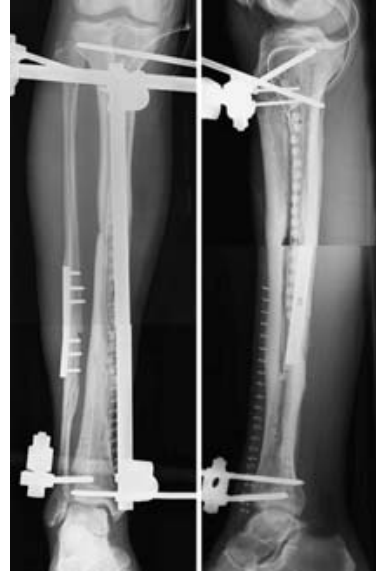

Abb. 5

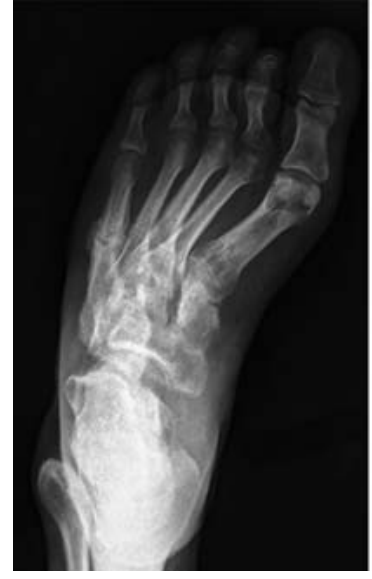

Abb. 6

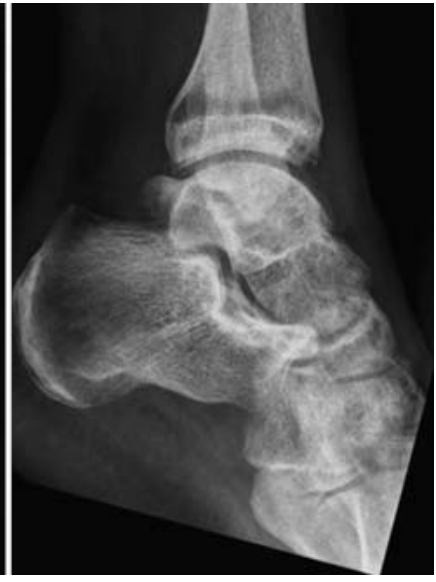

Abb. 8
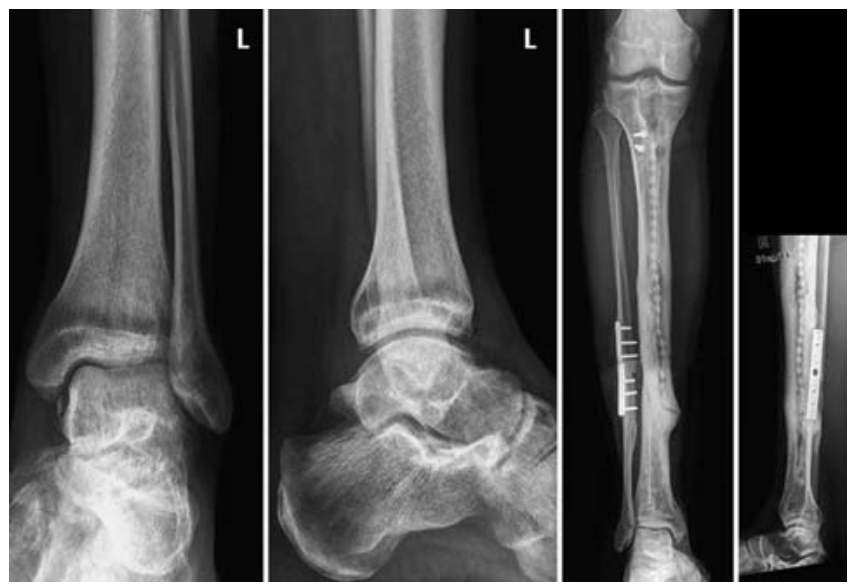

Abb. 9

Fazit

- Während des Bohrvorgangs bei der Marknagelung Hitzeentwicklung reduzieren durch Kühlung und scharfe Bohrsysteme, notfalls Eingriff abbrechen.

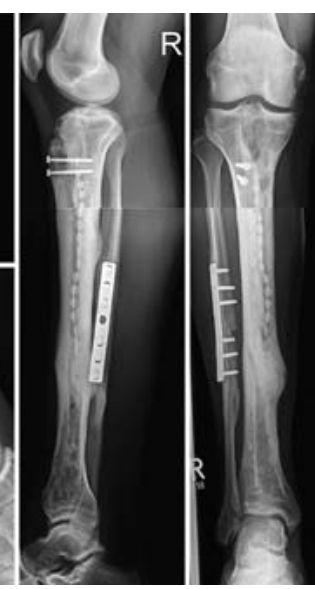

Abb. 10

- Bei Extraktionsproblemen einer notwendigen Marknagelentfernung auf Osteotomie vorbereitet sein (Aufklärung).

- Bei langer OP-Dauer (>3 Stunden) einem Kompartmentsyndrom der gesunden Extremität vorbeugen (Lagerung).

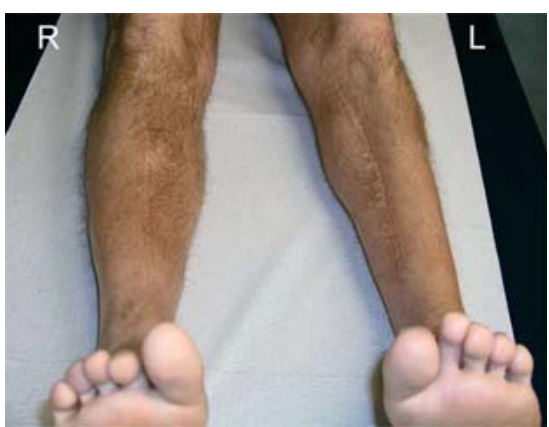

Abb. 11

Univ.-Prof. Dr. med.

Karl Heinrich Winker

Ärztlicher Direktor

Klinik für Unfall-, Hand- und

Wiederherstellungschirurgie HELIOS-Klinikum Erfurt

Nordhäuser Straße 74 99089 Erfurt

E-Mail: karl-heinrich.winker@ helios-kliniken.de 